\title{
Resolving equipment failure causes by root cause analysis and theory of inventive problem solving
}

\author{
Pablo Viveros ${ }^{1,2}$, Enrico Zio ${ }^{3,4}$, Christopher Nikulin ${ }^{5}$, Raúl Stegmaier' \\ and Gloria Bravo'
}

\begin{abstract}
Failure causes of production systems need to be readily identified, for effective recovery solutions. Root cause analysis can be used for this, integrated by a method for identifying coherent and sustainable solutions. In this article, root cause analysis for failure cause identification is coupled with a method of problem solving to guide the search for effective solutions, called theory of inventive problem solving. The integration of these methodologies is implemented and demonstrated on a real case concerning the solution to the potential failure of the equipment used in the torque test performed on truck engines used in high-tonnage mining operation. The incorporation of a key performance indicator analysis allows evaluating realistically the results obtained and determining the success of the solution.
\end{abstract}

\section{Keywords \\ Root cause analysis, theory of inventive problem solving, integrated methodology, high-tonnage mining operation}

Date received: 30 August 2012; accepted: 31 May 2013

\section{Introduction}

The work presented in this article falls within the maintenance and asset management areas, ${ }^{1,2}$ as represented by the eight-phase process ${ }^{3}$ described in the standard PAS 55-1:2008, ${ }^{2}$ which frames the course of actions to be achieved for ensuring efficiency, effectiveness and continuous improvement.

This article contributes to phase 3 of the process, aimed at defining immediate interventions on the weaknesses in equipment with high impact. The contribution investigates the use of root cause analysis (RCA) to identify the fundamental causes of failures or recurrent problems, which need to be corrected, including organizational and management deficiencies or omissions, and whose eradication would ensure that the failure does not repeat. However, RCA is not able to indicate a solution for the identified failure. To overcome this, we investigate the possibility of integrating RCA with the theory of inventive problem solving (TRIZ), which provides an analytical and systematic process for obtaining solutions to a problem. Solution to causes of failure of the equipment used in the torque test performed on truck engines used in high-tonnage mining operations is considered to demonstrate the applicability of the methodology.
Proactive maintenance utilizes tools such as RCA, failure modes and effects analysis (FMEA), critical analysis (CA) and others. There is a wide variety of tools and methods; however, this article presents those tools already accepted in the industry, which exhibit characteristics such as adaptability to cases of high or low complexity, systematic sequence and logic for its analysis and implementation, ability to integrate different specialties, among others. ${ }^{4}$

There is a wide variety of tools and methods for determining the root causes of certain events or failures. They vary in complexity, quality of information

\footnotetext{
'Departamento de Industrias, Universidad Técnica Federico Santa María, Valparaíso, Chile

${ }^{2}$ PHD Student, Department of Industrial Management, School of Engineering, University of Seville, Camino de los Descubrimientos s/n. 41092 Seville, Spain

${ }^{3}$ Chair on Systems Science and the Energetic Challenge, European Foundation for New Energy-Electricite' de France, Ecole Centrale ParisSupelec, Paris, France

${ }^{4}$ Department of Energy, Politecnico di Milano, Italy

${ }^{5}$ Dipartimento di Meccanica, Politecnico di Milano, Milano, Italy
}

\section{Corresponding author:}

Pablo Viveros, Departamento de Industrias, Universidad Técnica Federico Santa María, Av. España 1680, Valparaíso, Chile.

Email: pablo.viveros@usm.cl 


\begin{tabular}{|l|l|l|}
\hline \multicolumn{1}{|c|}{ Engine Type } & \multicolumn{2}{|c|}{$\mathbf{6 0}^{\circ}$ Vee, 16-Cylinder } \\
\hline Displacement & 3674 cu in & 60.2 liters \\
\hline Bore and Stroke & 6.26 in x 7.48 in & $159 \mathrm{~mm} \times 190 \mathrm{~mm}$ \\
\hline Oil System Capacity & 275 U.S. qt & 261 liters \\
\hline Coolant Capacity & $147.9 / 179.6$ U.S. qt & $140 / 170$ liters \\
\hline Aspiration & Turbocharged and Aftercooled \\
\hline Length & 114.8 in & $2916 \mathrm{~mm}$ \\
\hline Width & 62.3 in & $1582 \mathrm{~mm}$ \\
\hline Height & $79 / 92$ in & $2006 / 2337 \mathrm{~mm}^{\mathrm{a}}$ \\
\hline Dry Weight & $16612 / 19515 \mathrm{lbs}$ & $7535 / 8852 \mathrm{~kg}^{\mathrm{a}}$ \\
\hline Wet Weight & $17540 / 20514 \mathrm{lb}$ & $7956 / 9305 \mathrm{~kg}^{\mathrm{a}}$ \\
\hline
\end{tabular}

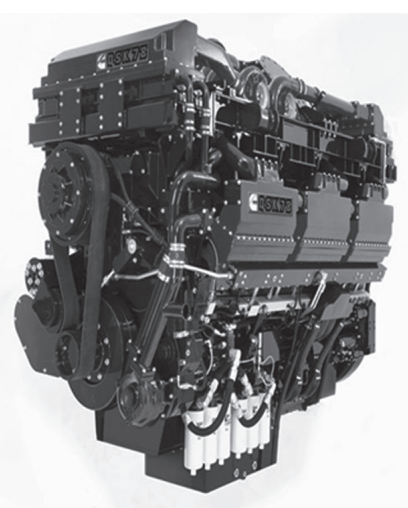

Figure I. Engine specifications (QSK60).

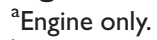

bSingle stage (two stage is turbocharged, aftercooled and intercooled).

required and applicability of their results. In general, the most commonly used are as follows: the 5-Why analysis, logic tree (PROACT), fault tree analysis (FTA), Bayesian inference and cause-and-effect diagram. ${ }^{5-11}$ These methodologies have substantial differences, and they can be categorized into qualitative (5 Whys Analysis, Ishikawa diagram and logic tree (PROACT)) and quantitative (Bayesian inference and FTA). While qualitative methods are generally performed in the form of brainstorming, quantitative methodologies can even use complex mathematical methods. The importance of using RCA tools in maintenance relies in the need to understand the main causes of failure on which management or operations may have some control, so that they can avoid the failure and returning to a specified plan of action. About inventive techniques for problem solving, the most useful in the industry are brainstormig, ${ }^{12,13}$ SCAMPER, ${ }^{14,15}$ creative challenge $^{6}$ and TRIZ. ${ }^{16}$

The motivation of this work is to propose a novel methodology, which constitutes a systematic procedure for tackling problems related to events that occur at high frequency and/or high impact. As a summary, this work proposes the combination of RCA and TRIZ for identifying failure causes and proposing effective solutions. The advantages associated with the use of RCA to identify the causes of a problem are presented in detail, and the benefits that TRIZ provides in finding the definition of their possible solution are highlighted.

According to the aims, this article is organized as follows: in section "Problem considered," the application and work proposal are introduced; in sections "RCA" and "TRIZ," the RCA and TRIZ methodologies are briefly summarized; in section "Results of the integrated methodology," the case study is presented and solved; some concluding remarks are given in section "Discussion."

\section{Problem considered}

We seek to find the cause that could damage the axle of a dynamometer used in the maintenance of mining engines and then identify a solution, so to avoid failure. The selection of the problem is because it has been, for a long time, a problem inside the company starting to be a chronic problem with nonobvious solution for operation team of the company. The main technical specifications of the mining engine (QSK60) are shown in Figure 1.

The process of mounting the engine on the dynamometer consists of many stages, because it is not possible to mount the motor directly. First, one must remove the male drive shaft of the dynamometer, and then this drive shaft should be attached to the coupling plate (using for this a nut-bolt clamping) because both male drive shaft and coupling plate have perforations without thread. Once completed, the set engine drive shaftplate should be attached to the engine test. For this union, the coupling plate is set to the engine using a clamp bolt because the coupling plate perforations have no thread; on the contrary, the steering wheel perforations have threads. For carrying out the process, all the steps mentioned must be performed outside the torque room because of the space required and the weight of the pieces.

Finally, with all the pieces assembled, the engine is entered into the torque room, and the set drive shaftplate-steering wheel is connected to the female drive shaft. This stage is difficult to perform because the pieces are very heavy and are not always tightly coupled between the male and female drive shaft (Table 1). A schematic representation is shown in Figure 2.

Table I. Description of parts that make up the torque test before implementing the solution to avoid failure.

\begin{tabular}{ll}
\hline Piece number & Description \\
\hline 1 & Female drive shaft axle \\
2 & Male drive shaft axle \\
3 & Coupling plate \\
4 & Joint nut-bolt drive shaft-plate set \\
5 & Joining bolt plate-steering wheel set \\
\hline
\end{tabular}




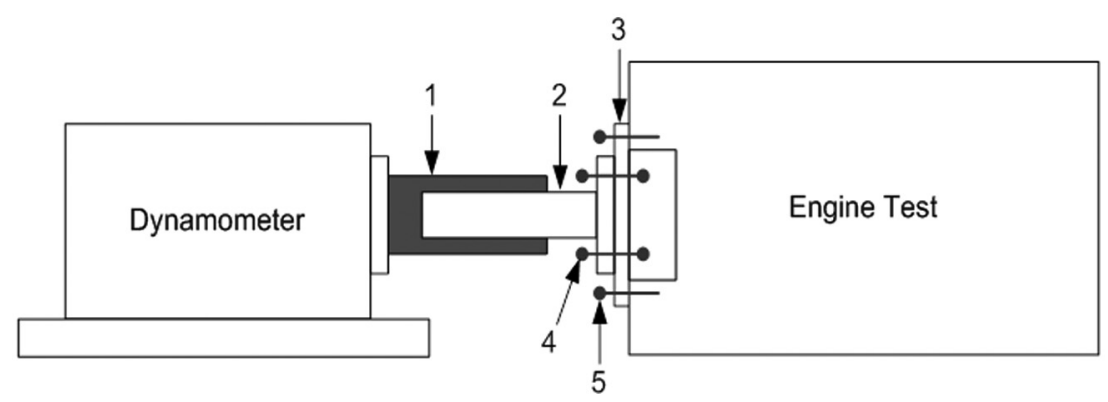

Figure 2. Parts and pieces that form the dynamometer or torque test, before implementing the solution to avoid failure.

As we shall explain in the following, the RCA methodology is a tool for identifying the root causes of a problem, but it does not systematically address the solution. There are case studies for maintenance tools and TRIZ, but none provides a repeatable or confinable method of integration. ${ }^{17}$ On the other hand, TRIZ provides a theoretical framework for generating creative solutions to problem, but does not identify the root causes. Then, the shortcomings of RCA and TRIZ can be overcome by their integration. Figure 3 shows the flowchart of the integration of RCA and TRIZ proposed in this article.

\section{Gathering information}

The engine maintenance process consists of four main phases:

1. Receiving of the engine unit: includes receiving, control and evaluation of the current condition of the engine.

2. Repair process: parts and key pieces are checked to perform their maintenance.

3. Finished product: performing the dynamometric or torque test. This test is the final verification stage, where the engine is measured and regulated on power, torque, revolutions per minute (RPM), air volume, fuel volume and oil volume.

4. Postdelivery: this phase includes a follow-up to the repaired engine and customer satisfaction.

It has been seen that the finished product stage is one major bottleneck in the maintenance of engines. This is mainly due to the implementation of the torque test, and its effect is significant considering that all engines must undergo the maintenance process, and that there is typically only one dynamometer at the facilities.

\section{Identify the problem}

The torque test is essential for the engine maintenance process. And given that there is typically only one dynamometer available, its failure could significantly delay completion of the maintenance process. Among the different ways in which this equipment can fail (failure modes), the most catastrophic would be to break its axle. Thus, the main problem is defined as the failure mode "Dynamometer axle breakage."

\section{Determine the significance of the problem}

It has been seen that the finished product stage is one major bottleneck in the maintenance of engines. This is mainly due to the implementation of the torque test, and its effect is significant considering that all engines must undergo the maintenance process, and that there is typically only one dynamometer at the facilities.

In the situation considered, there is only one dynamometer for torque testing as it is a very expensive piece of equipment. Breaking the axle of this equipment is a critical failure mode of high impact, because if this were to occur the cost of replacing the axle of the dynamometer is very high. Furthermore, it brings a high risk to the operators who perform the test and may even cause a fatal accident. Therefore, this problem is defined as critical, of high impact.

\section{RCA}

The RCA has been shown useful in various practical applications, thanks to its capability of the following:

- Proactively avoiding recurrent failures of highimpact operating and maintenance costs.

- Reactively solving complex problems that affect an organization.

- Analyzing repetitive failures of equipment or critical processes.

- Analyzing human errors when designing and implementing procedures.

The benefits brought by the use of RCA are as follows: ${ }^{5,19}$

- Reduction of the number of incidents and failures.

- Reduction of expenses and deferred production associated with failures.

- Improvement of reliability, safety and environmental protection.

- Improvement of efficiency, profitability and productivity. 

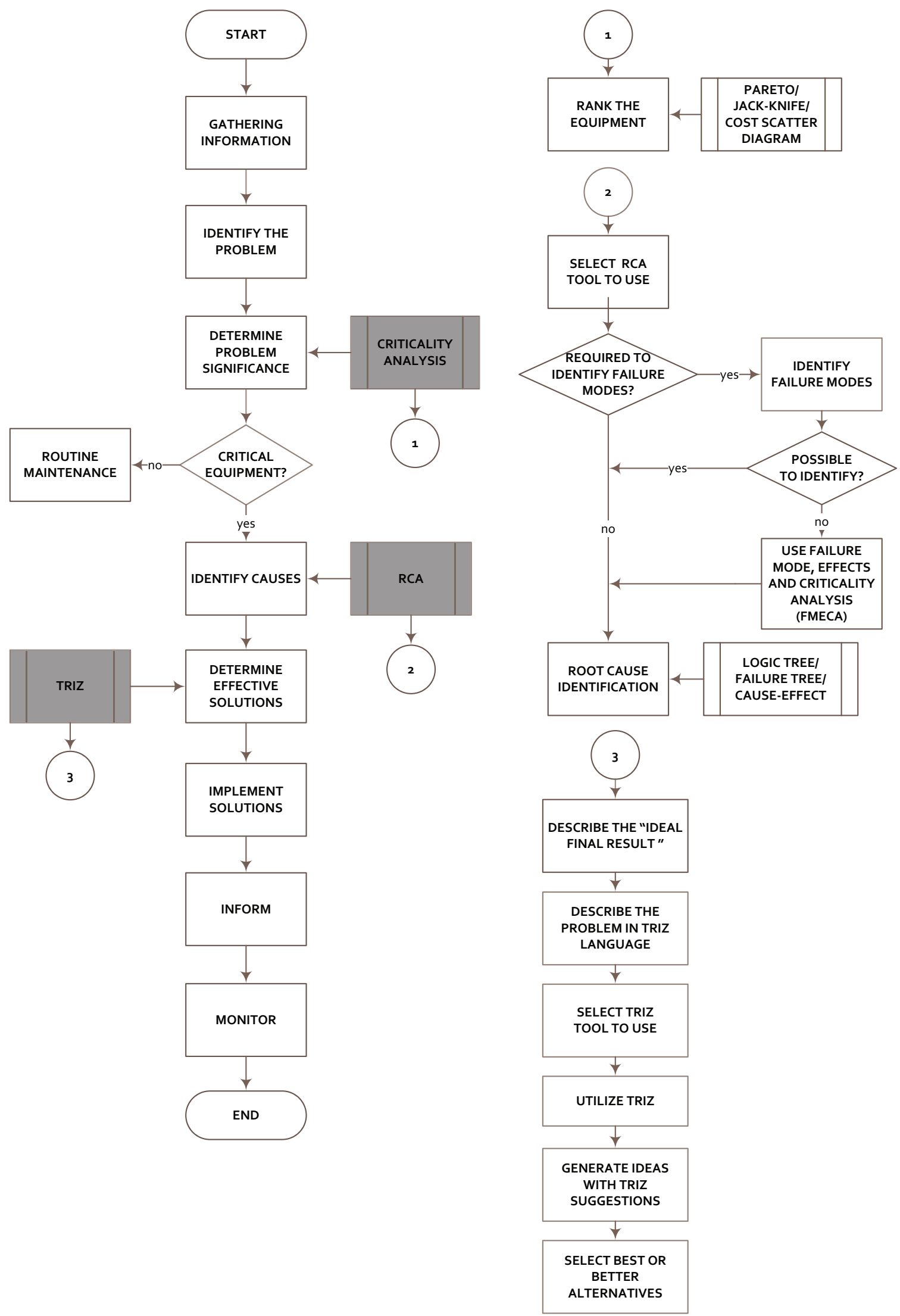

Figure 3. Flowchart integration of RCA-TRIZ.

RCA: root cause analysis; TRIZ: theory of inventive problem solving. 


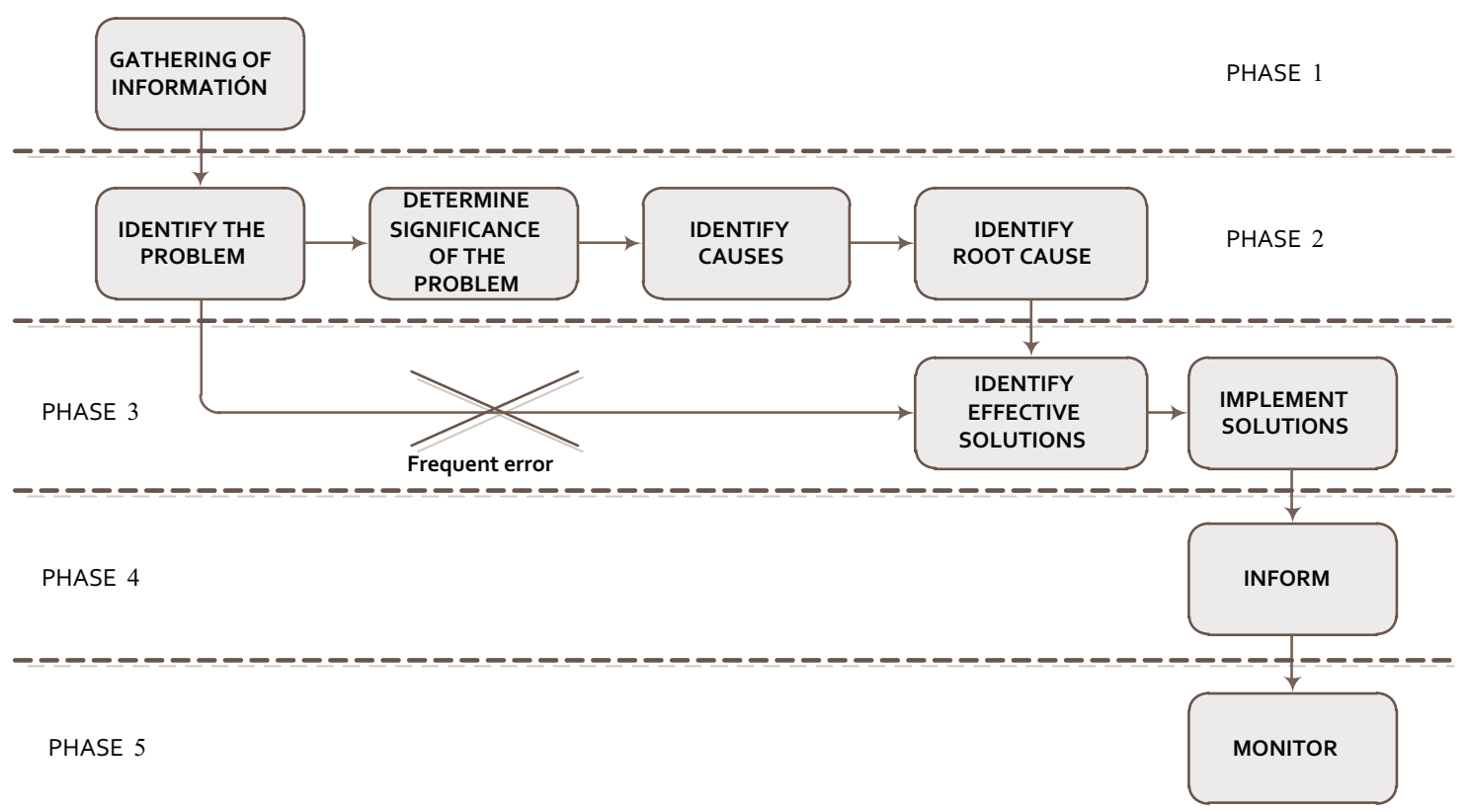

Figure 4. RCA methodology.

RCA consists of five phases (Figure 4). ${ }^{6}$ As shown, the solution of the problem is defined directly from the definition of the problem itself, without developing a thorough analysis of its root causes.

For RCA, various tools and techniques can be used to detect the root cause of a problem. Some of them are briefly described below.

\section{Logic tree $(\text { PROACT })^{5,7,19}$}

This method organizes the logic structure of the chain of causes and effects, from the event of failure or problem until the basic causes that produce it (deductive analysis). The logic tree structure is shown in Figure 5.

The event of failure or problem is an undesirable condition of the system. It constitutes the starting point of the analysis and should state a factual event, not an assumption. Failure modes of how the event occurs ${ }^{21,22}$ are then identified. In RCA, the failure modes should be facts and not hypotheses, that is, they must have been previously verified.

Finally, the logic tree develops into the root cause of each failure mode. Typically, there are three types of causes:

- Physical. Failure mechanism of the component. It is the cause that creates the failure directly. Often, at this level, the root cause of the failure may not be found, but only a starting point to locate it.

- Human. Human error that impacts directly or indirectly on the failure occurrence.

- Latent. Demonstration of the organizational processes that explain the occurrence of human root causes. Only its eradication guarantees that the failure is not repeated.

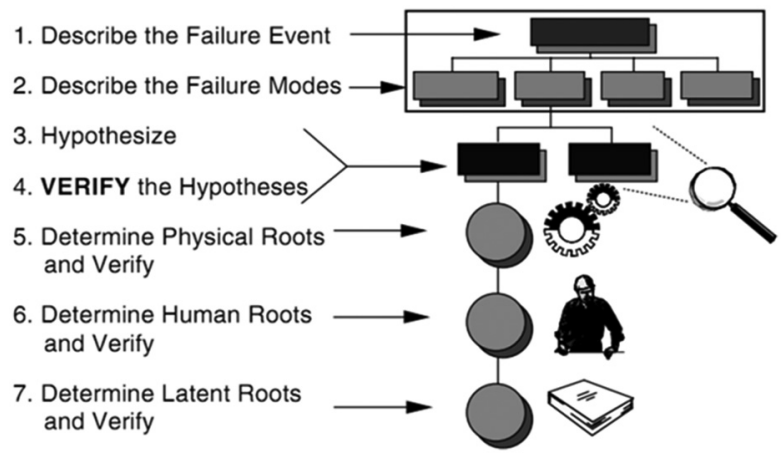

Figure 5. Logic tree structure. ${ }^{8}$

FTA $^{8,9,22}$

A fault tree is a graphical representation of the logical relationships between events of failure, where the main top event is branched into events that contribute to it through the analysis of causes and effects. FTA is a deductive process: from the top event, the other occurrences are deducted.

FTA can provide both qualitative and quantitative information about the system under study. Qualitative information can include paths of failure, root causes and weak areas of the system.

Quantitative analysis provides a probabilistic estimate of the occurrence of the top event. The analysis also provides measures of the importance of the paths through which the causes are propagated to the top event, indicating critical areas where corrective actions are required. 


\section{Cause-and-effect diagram ${ }^{6}$}

This technique, also called "Analysis of the events and causal factors," is used for multifaceted problems or long chains and complex causal factors. The resulting picture is a cause-and-effect diagram describing the timing of a series of tasks and/or actions and the environmental conditions leading to an event. First, the problem must be defined and the main effect identified; then, the question must be asked, "Why does the effect occur?" and responded with the causes. The effects become causes as it is asked "Why?" which generates a chain. In this diagram, there are two types of causes: action and condition. The action cause triggers the condition cause to generate the primary effect.

\section{The 5-Why technique ${ }^{\prime \prime}$}

The 5-Why technique, also called Why-Why Diagram, illustrates a chain of symptoms that lead to the cause of a problem. The technique consists of observing an undesirable result and from this event asks why it did happen. Once the question is answered, the next question is, Why did that happen? And so on, through the levels necessary for finding an acceptable root cause. Often, it takes at least five levels of Why? to determine the root cause, hence the name of the technique.

Implementation of this technique is generally made by a domain expert working group for answering the questions. Responses must be statements of the causes contributing to the problem under discussion, according to the group.

When the Why? questions are asked, it is important that Who? questions should not start being asked, because the team must be interested in the process and not the person involved. However, once the causes are determined, the summary table can be extended including records that indicate who will be responsible for carrying out these actions and when they must be completed.

The efficacy of application of different tools depends on the level of information available and the detail which is requested by the analysis. Furthermore, there are other methods that can be used as complementary support of RCA. For more details, see section "Complementary tools for root cause analysis" in Appendix 1.

\section{TRIZ ${ }^{16,23,24}$}

TRIZ (Teoriya Resheniya Izobretatel skikh Zadatch, Russian language) is the Russian acronym now used internationally for "Theory of inventive problem solving." 16 The basis of the methodology is in the works and empirical studies of the Russian scientist Altshuller Genrich, who found that the shape of an invention follows certain laws. To test this hypothesis, Altshuller analyzed more than 200,000 invention patents to try to understand what actions were taken into account to patent any new knowledge. Altshuller concluded that from the total number of patents analyzed, only 40,000 had some inventive solutions, while the rest were only direct improvements. Moreover, he realized that particular actions were repeated in one or more patents, which he called inventive principles.

TRIZ is based on five key philosophical elements, which are as follows:

1. Ideality. It is the fundamental criterion to measure the excellence of a system; it is based on maximizing the profits provided by the system and minimizing the harmful effects and costs of resource associated with the system

$$
I_{(U F, C, H F)}=\frac{\sum_{i=1}^{n} U F_{i}}{\sum_{j=1}^{m} C_{j}+\sum_{k=1}^{w} H F_{k}} ; \quad \forall i, j, k \geqslant 1
$$

where $U F_{i}$ is utility function of the each useful function of the technological system; $C_{j}$ is cost function of the resource to obtain the main useful function (MUF) for all the components of technological system; $H F_{k}$ is cost function of the harm functions, which has the system for obtain the MUF. The higher the ratio, the greater the ideality.

2. Modeling of functions and functional analysis. A function is defined as a natural action or a characteristic performed by a product or service. Generally, a product or service provides many functions, which can be modeled and analyzed in different ways, for example:

- Functional analysis diagram. A function can be described and analyzed using a graphical tool called "functional analysis diagram." This diagram consists of three essential elements: a subject, which is the source of action; an object, which is receiving the action, and an action (verb), which is represented by an arrow. In a technological system, the "action" is usually performed by applying some type of field, for example, mechanical, electrical and chemical.

- Substance-field analysis. Another tool used for modeling of functions and functional analysis is the "substance-field analysis." In this model, there are three essential elements: substance $1(\mathrm{~S} 1)$, article, which is equivalent to the "object" in the diagram of functional analysis; substance 2 (S2), tool, which corresponds to the "subject" in the diagram of functional analysis; field (F) represents the energy field between the interaction of S1 and S2.

3. Resources. According to TRIZ, the resources are classified into four families: Space resources (places, zones, free areas, etc.), Substance resources 
(every physical element in the environment or inside the system studied), Field resources (every physical field present in the environment, mechanical, thermal, chemical, electrical or magnetic) and, finally, Time resources (instants, time intervals between actions, etc.). ${ }^{25}$ Another author has increased the number of resources to five, by adding the resource Information. ${ }^{26,27}$

4. Contradictions. ${ }^{16}$ Two types of contradictions are identified for technical system problem:

- Technical contradiction. A technical contradiction is a situation where efforts to improve some of the technical attributes of a system lead to a deterioration in other technical attributes. For example, increasing the engine power of a car (desirable attribute) can cause increased engine weight (undesirable attribute).

- Physical contradiction. A physical contradiction is a situation in which a subject or an object is in two mutually exclusive physical states.

A physical contradiction is the typical pattern: "To perform the function $F 1$, the element must have the property $\mathrm{P}$, but to perform the function $\mathrm{F} 2$, it must have the property -P, or the opposite of P." For example, a car must be light (P) to be fuel efficient (F1), but it has to be heavy (-P) to be a stable and manageable car (F2).

5. Theory of evolution of technological systems. ${ }^{16} \mathrm{~A}$ technological system is anything capable of performing a specific task, for example, a vehicle, a space station, a power plant and so on. Technological systems are organized hierarchically, ${ }^{28}$ that is, any technological system contains subordinate systems and the system itself is a subordinate of a larger system (supersystem); thus, a change undergone by the system affects both the subsystem and the supersystem.

The evolution of technological systems is due to well-defined patterns of perfectly predictable stages. In this sense, the whole technological system goes through four stages during its evolution, which refers to the changes undergone by the system over its useful life: Infancy, Growth, Maturity and Decline. The main features of the TRIZ methodology are described in Appendix 2.

\section{Results of the integrated methodology}

\section{Identify the causes}

According to problem described in the previous sections, in this step is necessary to understand why is needed the application of one of the RCA tools. The analysts have to identify the best RCA tool according to the available information, time and expertise. Description of the RCA for the case study is given below:

- Select the RCA tool to use. This sub-step attempts to select the best RCA tool to describe the problem situation, identify the failure modes, cause and effect of the system and so on. This is relevant to provide future analysis using TRIZ.

The tool used to analyze this case study is the logic tree (PROACT). ${ }^{7}$ Mainly, it is a systematic methodology that can be useful for analyzing both high-impact events (as in this case) and high-frequency events and allows identifying not only the physical causes of the failure but also human errors that lead to failure. Moreover, it backtracks the organizational problems that explain the occurrence of human errors, thus, in the end, identifying the three types of root causes: physical, human and latent.

- Identify the failure modes. A failure mode is a single event that causes a functional failure. It is the mechanism that expresses the problem or failure. ${ }^{20,21}$ This sub-step helps to considerer different failure modes or problems involved in the system using RCA. According to the case study, there are several ways in which the dynamometer can fail, the most catastrophic being the breakage of its axle; this is the one here be considered.

- Identify root causes. This sub-step attempts to clarify to the analyst all the possible causes and effect related with the specific failure mode and problem.

The logic tree applied for the failure mode "dynamometer axle breakage", developed with the symbols of Figure 5, is shown in Figures 7-11.

Finally, a clear situation of the problems, failure modes and causes is provided. This information will be used in the next step as requirement to identify a desirable solution.

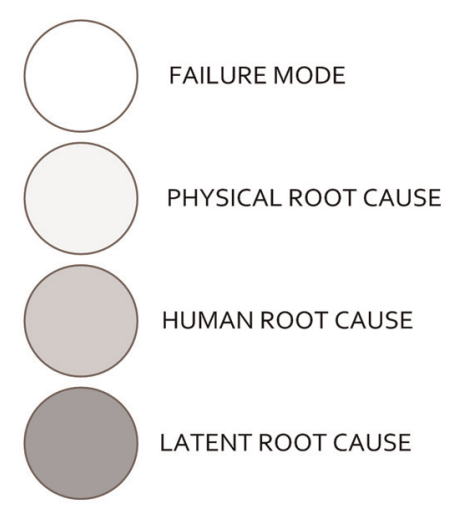

Figure 6. Symbols used in the logic tree. 


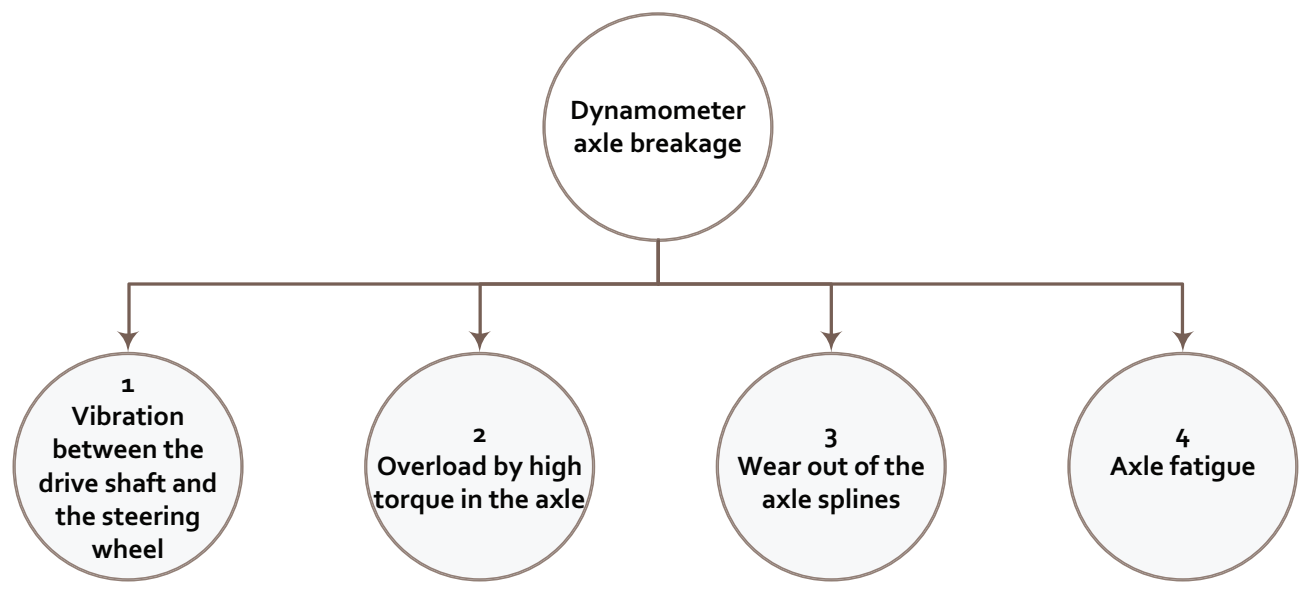

Figure 7. Logic tree. Breakage failure mode of the dynamometer axle and physical root causes.

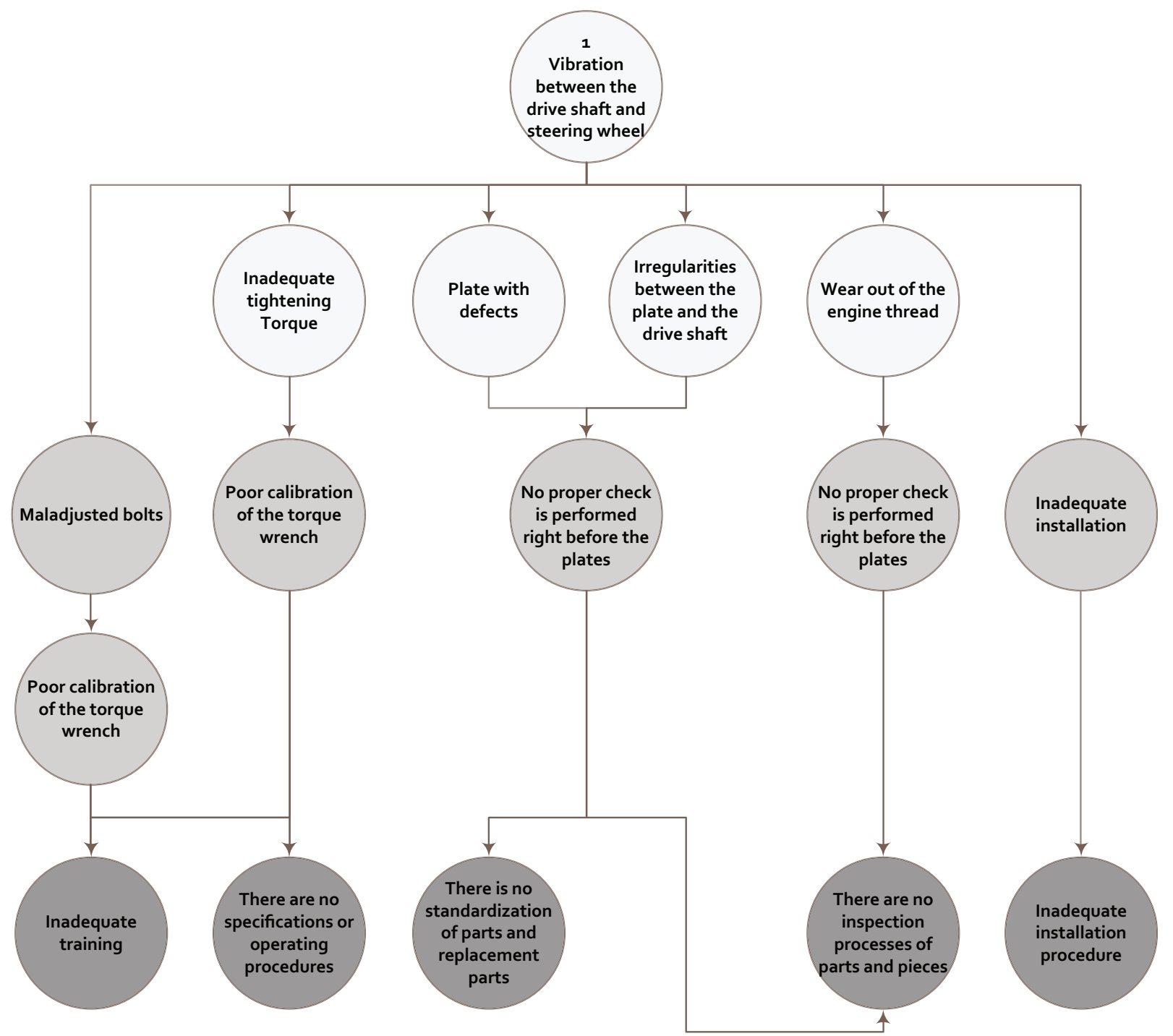

Figure 8. Logic tree. Physical root cause: vibrations between the drive shaft and steering. 


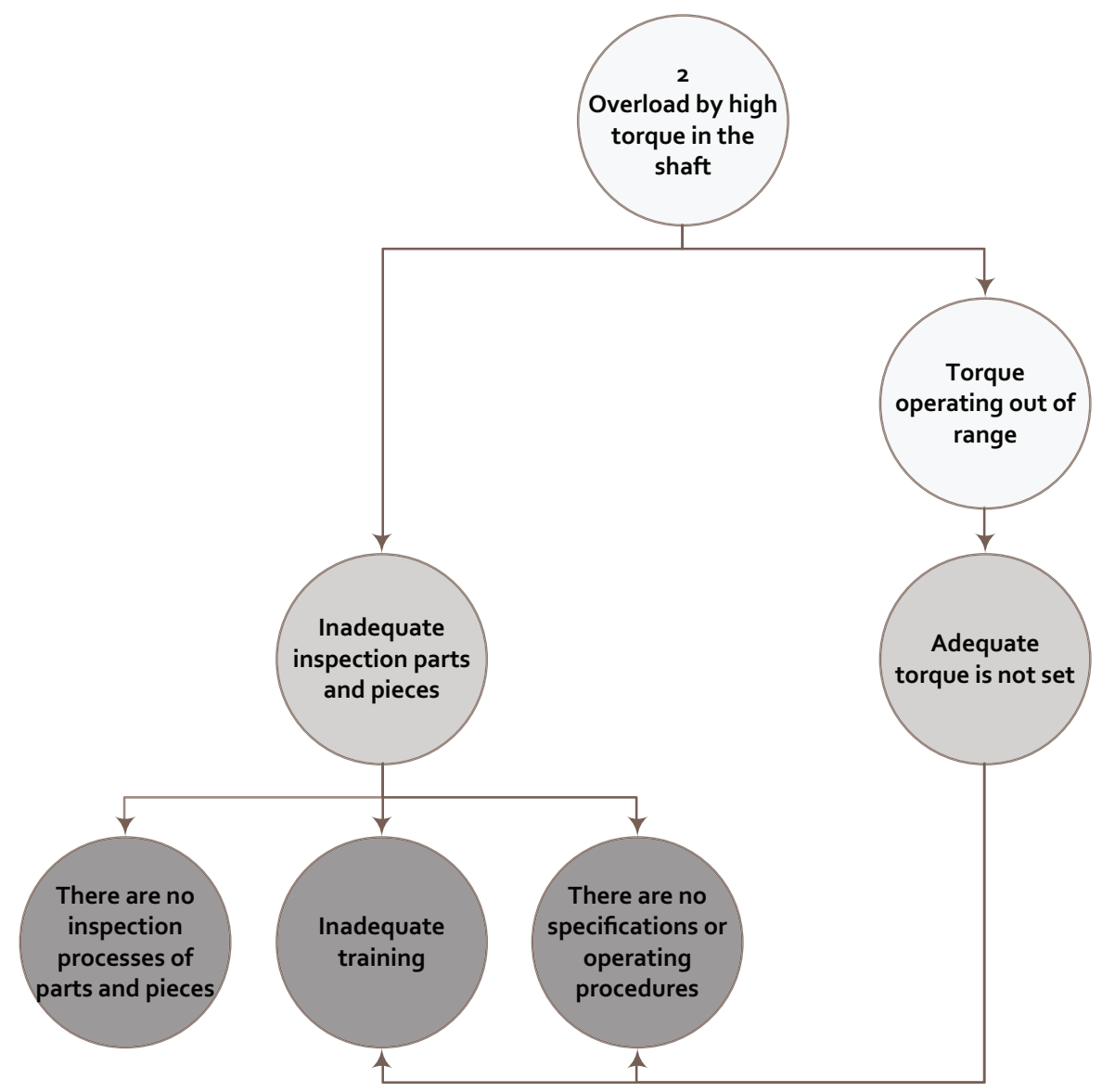

Figure 9. Logic tree. Physical root cause: overload for high torque on the axis.

\section{Identify effective solutions}

In this step, it is necessary to understand which are the desired results or requirement of possible solution. Constrains of the problem are related with the main failure mode and causes. According to the RCA for the case, the failure mode "axle breakage" is related with the human root causes, specifically with "Inadequate installation procedure" cause (Figure 11). Moreover, experts in the work area justified it by the fact that it is considered the main cause of the problem in the equipment.

To create and identify a possible solution, the following sub-steps are provided:

- Describe the "Ideal Final Result." This sub-step attempts to identify the desired results of the possible solutions and requirement for the implementation. The case study can be divided into two main issues:

1. The solution of the problem should allow a safer and easier procedure to mount the engine on the dynamometer.

2. The solutions have to avoid the problems that can cause the rupture of the dynamometer axle when the torque test is performed.
- Describe the problem in TRIZ language. This substep is necessary to identify the possible changes and possible undesired effects according to the requirements. This sub-steps help to identify the contradictions involved in the problem:

Contradiction 1. If the solution changes the way in which the assembly process is made, the assembly can be made easier (desirable attribute) but may decrease the measurement accuracy of the dynamometer (undesirable attribute).

Contradiction 2. If the solution changes a part of the equipment, the assembly can be made easier (desirable attribute) but the coupling procedure may be complex and therefore very expensive (undesirable attribute).

Selection of TRIZ tool to use. In this sub-step, the TRIZ tool has to be selected to solve the contradiction identified in the previous sub-step. In the case study, the inventive principle and matrix contradictions to analyze the problem were selected, mainly because the problem considerers technical and administrative contradictions (see details in Appendix 2)

Utilize TRIZ. The contradictions can be described in different ways according to the selected TRIZ tool and strategy to assess the solution. ${ }^{24}$ 


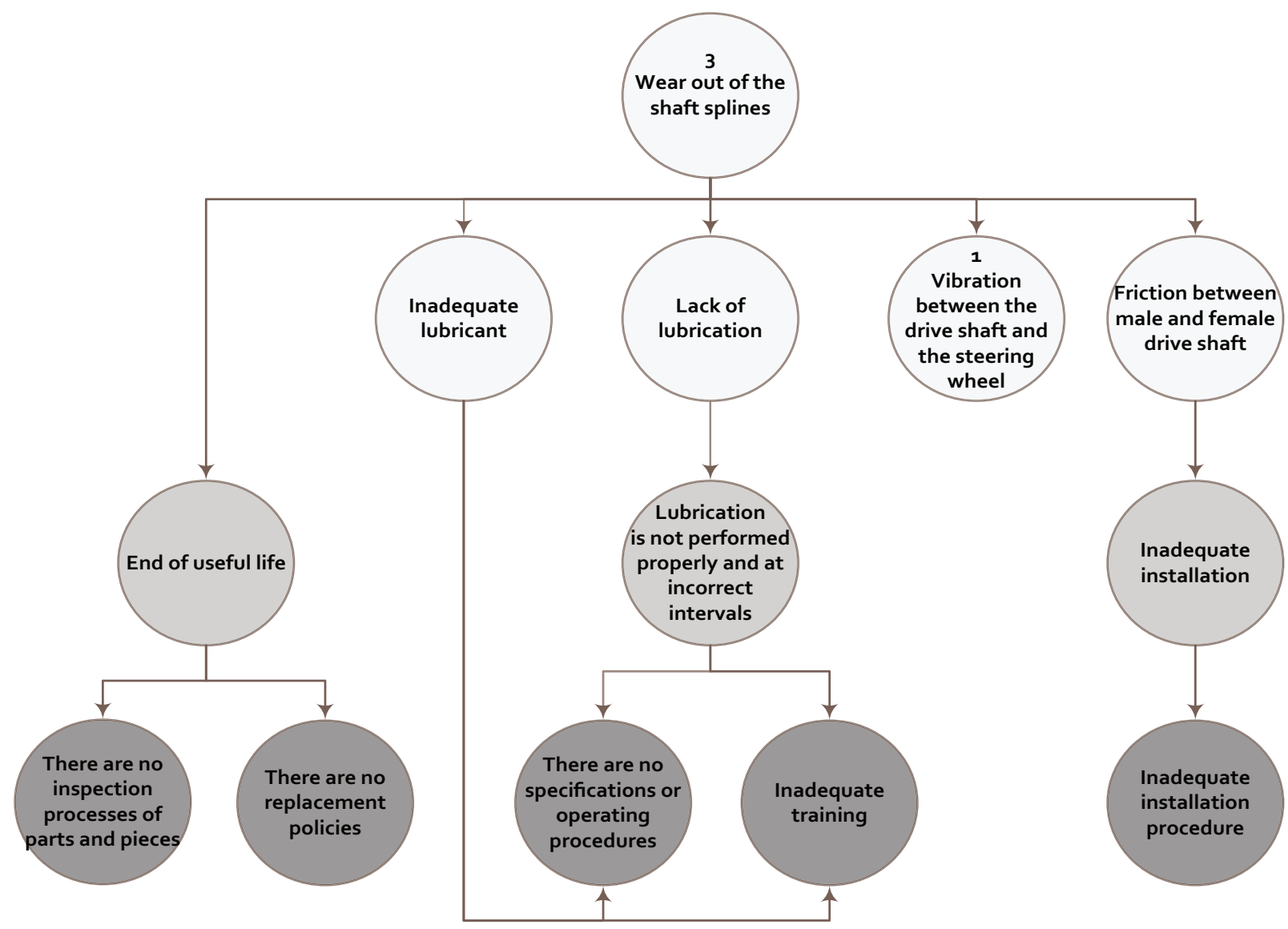

Figure 10. Logic tree. Physical root cause: wear out of axle splines.

To use the matrix of contradictions, the engineering parameters of TRIZ must be identified. According to the contradictions previously defined, it is necessary to identify the parameters that can be improved and/or worsen (Table 2). Each parameter provided by Altshuller has an explanation to clarify the main concept at moment to apply.

Using these parameters, the pairs for the matrix of contradictions are generated (Table 3). Finally, a set of principles and examples are given for this specific TRIZ tool as recommendation to solve the current problem. ${ }^{24}$

Analysts need to identify which principles can be used according to the context of the problem; the details of the principles applied to the case study are described in the following:

1. Principle 1: segmentation

Divide an object into independent parts.

Make object easy to disassemble.

Increase the degree of fragmentation or segmentation.

2. Principle 17: another dimension

Move an object on a two-dimensional or threedimensional space.

Use an array of objects from multiple levels instead of an array of one level.

Tilt or reorient the object, putting on its side.
Use the "other side" of a given area.

3. Principle 24: mediator

Use an intermediate transporter object or intermediary process.

Attach an object temporarily with another (which can be easily removed).

- Generate ideas with TRIZ recommendations. The analysis of the proposed inventive principles, ideas and guidelines is performed to generate a solution to the problem raised.

1. Principle 1. It is suggested to make the object easy to disassemble and/or increase the degree of fragmentation or segmentation. To increase the degree of fragmentation, one or more parts or pieces could be incorporated into the mounting system, to form a quick coupling connections system.

2. Principle 17. It is suggested to use an array of objects from multiple levels, instead of an array of one level. The current mounting system consists of two main levels, which are the male axle drive shaft and the coupling plate: a third level could be added to this, which would consist in another plate being joined.

3. Principle 24. It is suggested to use an intermediate object and/or attach an object temporarily with another. The intermediate object 


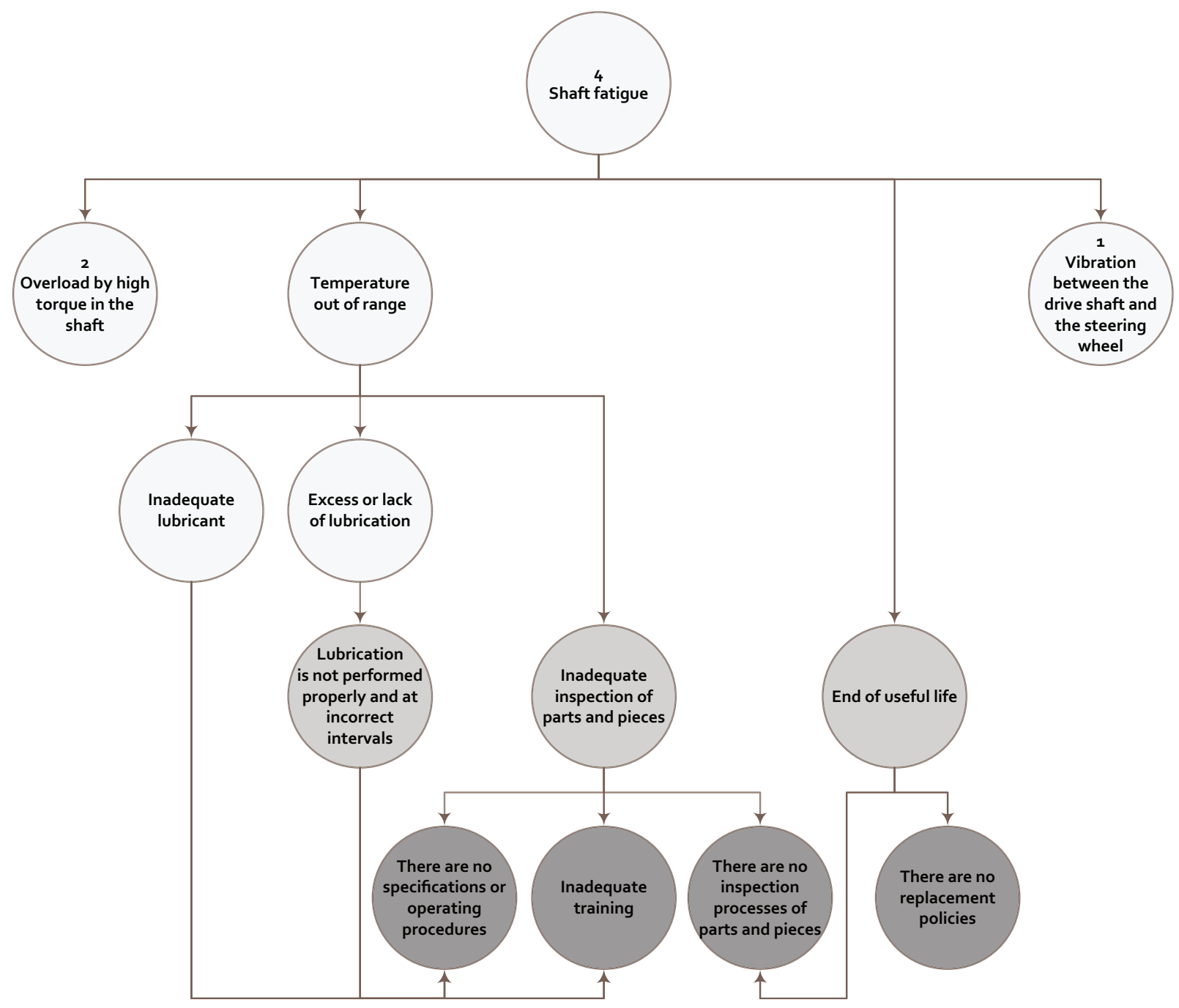

Figure II. Logic tree. Physical root cause: fatigue of the axle.

Table 2. Identification of the engineering parameters of $\mathrm{TRIZ}{ }^{25}$

\section{Parameter that improves}

33. Ease of operation: simplicity and ease of operation. The technique is not convenient if it requires many steps to operate or needs special tools, many highly skilled workers and so on; often a convenient process has high yield due to the possibility to do it right
Parameter that worsen

28. Measurement accuracy: the closeness of the measured value to the actual value of a property of a system; reducing the error in a measurement increases the accuracy of the measurement

36. Complexity of device: the number and diversity of elements and element interrelationships within a system. The user may be an element of the system that increases the complexity

Table 3. Results of the inventive principles of TRIZ.

\begin{tabular}{llll}
\hline $\begin{array}{l}\text { Pairs of parameters: } \\
\text { engineering contradictions }\end{array}$ & Inventive principles & $\begin{array}{l}\text { Pairs of parameters: } \\
\text { alternate contradictions }\end{array}$ & $\begin{array}{l}\text { Inventive } \\
\text { principles }\end{array}$ \\
\hline$(33,28)$ & $25,13,2,34$ & $(28,33)$ & $1,13,17,34$ \\
$(33,36)$ & $32,25,12,17$ & $(36,33)$ & $27,9,26,24$ \\
\hline
\end{tabular}


Table 4. Description of parts that make up the torque test with the solution implemented.

\begin{tabular}{ll}
\hline Piece number & Description \\
\hline 1 & Female drive shaft axle \\
2 & Male drive shaft axle \\
3 & Intermediate plate \\
4 & Coupling plate \\
5 & Joining bolt drive shaft-intermediate \\
6 & plate-plate set \\
7 & Joint nut-bolt intermediate plate-plate set \\
\hline
\end{tabular}

could be another plate that is joined to another piece, either to the coupling plate or to the male drive shaft.

Considering each of the above principles, the proposed solution is as follows: incorporate a flange (intermediate plate) that is attached to the coupling plate, in the one that allows a direct union with the male drive shaft. The intermediate plate has threaded perforations that allow the male drive shaft to join with the coupling plate using fastening bolts, and not fastening bolt-nuts as used previously. In addition, the intermediate plate has a higher number of perforations, which reduces the possible looseness of bolts due to vibration.

The solution conceived facilitates the assembly process of the engine in the dynamometer, in addition to significantly reducing the time required for this process. This is because, thanks to the intermediate plate, it is not necessary to remove the male drive shaft axle of the dynamometer to make the assemblage.

The way in which the intermediate plate assembles is as follows. The intermediate plate is attached to the coupling plate; the assemblage plate-intermediate plate is attached to the steering wheel of the engine test (a process that can be done in advance). At the time of the test, the set plate-intermediate plate is entered to the torque room. Then, the male drive shaft axle is slightly removed from the female one and is joined by a fastening pin to the plate-intermediate plate-steering wheel set (Table 4). The details of these joints are shown in Figure 12.

Selecting best or better alternative( $s)$. The solution generated following the recommendations found by the implementation of TRIZ amounts to a system of intermediate plate (flange), which connects two parts, the male drive shaft with the coupling plate. Other solutions could be identified similar to this one and which should be compared in order to analyze, which alternative generates the highest positive impact, with least complexity and lowest cost. Some possible alternatives are as follows:

Alternative 1. Intermediate coupling system that joins two parts (the male drive shaft and the coupling plate). This solution would keep the current coupling plates, and only minor modifications should be made to these plates, consisting of a series of perforations.

Alternative 2. Independent coupling system (completely new) with all the basic features of assembling and disassembling of its parts. This solution would discard the current coupling plates, as these would not be necessary any longer.

Alternative 3. This alternative is similar to Alternative 2. It consists of an independent coupling system (completely new) with all the basic features of assembling and disassembling of its parts, but this system would be a universal coupling, that is, it could be used in all types of high-powered engines.

To evaluate the solution concepts, a modification of the mathematical forms used by Ulwick ${ }^{20}$ in the "algorithm opportunity" is used; this algorithm can identify five main steps: survey instrument (brief explanation of the solutions concepts to the experts); target population (mining company); rate of the participants; degree of the variables (percentage range for acceptation of the solution: $0=$ lower and $100=$ high) and opportunity equation and constrains. These alternatives are compared in Table 5 according to the expected outcome of each one, as specified by the expert choices.

Subsequently, an analysis is completed to determine the alternative that represents a major opportunity for development, according to three parameters:

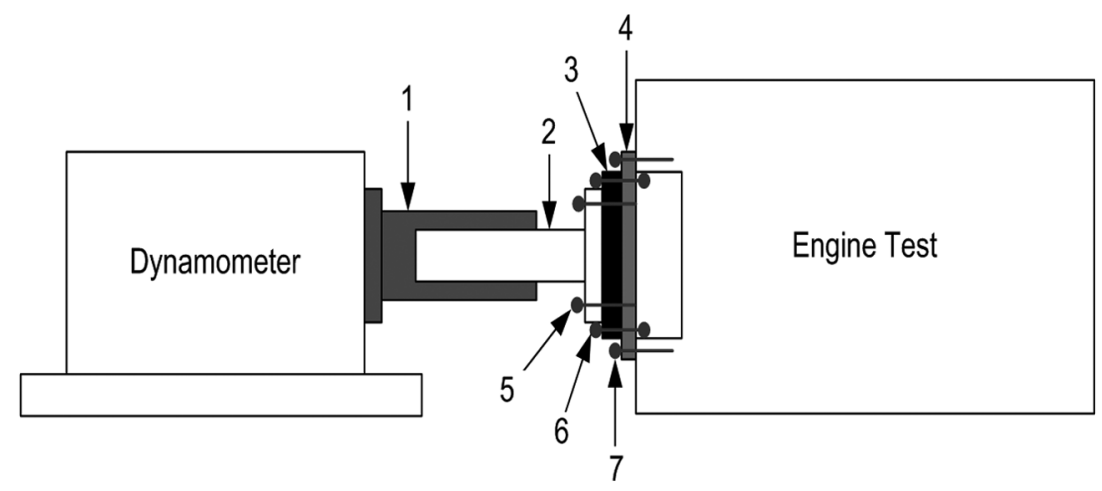

Figure 12. Parts and pieces that make up the torque test with the solution implemented. 
Table 5. Comparison of alternatives.

\begin{tabular}{llrr}
\hline Expected outcome & Alternatives & & \\
\cline { 3 - 4 } & 1 & 2 & 3 \\
\hline Reduce downtime due to the assembly of parts (\%) & 60 & 70 & 70 \\
Reduce torque which affects bolts (\%) & 50 & 50 & 50 \\
Prevent wear out on the coupling drive shaft (\%) & 80 & 70 & 80 \\
Prevent the looseness and fatigue of the bolts (\%) & 70 & 80 & 80 \\
Minimize bad torque test measurements (\%) & 62 & 76 & 76 \\
Average score (degree of impact of the innovative solution) (\%) & 62 & 80 \\
\hline
\end{tabular}

Table 6. Development opportunity analysis.

\begin{tabular}{lllll}
\hline Alternative & $\begin{array}{l}\text { Utility function degree of impact } \\
\text { of the solutions concept } \\
\text { in the process }{ }^{\mathrm{a}} \text { (\%) }\end{array}$ & $\begin{array}{l}\text { Utility function } \\
\text { (complexity in } \\
\text { manufacturing) }\end{array}$ & $\begin{array}{l}\text { Function associated } \\
\text { with the manufacture cost } \\
\text { of the solutions }\end{array}$ & $\begin{array}{l}\text { Utility function for the } \\
\text { development opportunity } \\
\text { from concept solutions } \\
\text { inside the company }{ }^{\text {b }} \text { (1) }^{\text {(\%) }}\end{array}$ \\
\hline 1 & 62 & 50 & 485 & -12.59 \\
2 & 76 & 70 & 3.107 & -151.38 \\
3 & 76 & 100 & 2.330 & -142.03 \\
\hline
\end{tabular}

${ }^{a} U$ tility function is measured in terms of satisfaction of the solution for the decision makers in the case of the study in percentage. ${ }^{b}$ Development opportunity is calculated by modifying the utility function according to the problem and situation: ${ }^{21}$

$U_{\text {(Development opportunity) }}=U_{(\text {level of impact) }}-\left(U_{(\text {complexity) }}+U_{(\text {(solution costs/average cost }) \times 100)}\right)$.

- The requirements of the company: According to the requirements of the company, which are listed in Table 5, the level of impact of the innovative solution is obtained.

- The degree of complexity of the solutions: complexity in comparative terms. The maximum is $100 \%$, which corresponds to the system implementation choice that has most complexity from the technical point of view.

- Associated costs: cost in dollars of the system to implement. For Alternatives 1 and 3, the cost corresponds to the value of one coupling system; for the cost of Alternative 2, it is the value of two coupling systems because it requires at least a double amount of plates, and also this solution is not a universal system, which then varies depending on the engine.

According to the values of development opportunities, identified in Table 6, the best solution corresponds to the solution with highest value, because this solution present less constrains for the implementation according to the criteria of the team inside the company. The best solution from the point of view of the company is Alternative 1, which corresponds to the intermediate coupling system.

\section{Implement solutions}

As mentioned previously, some modifications must be made to the existing coupling plates. These amendments are to achieve 10 perforations $5 / 8^{\prime \prime}$ every $36^{\circ}$ at a

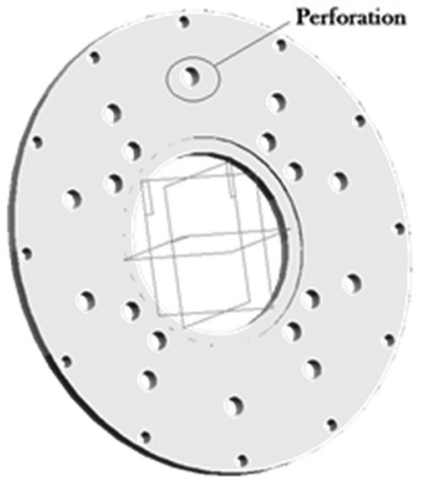

Figure I3. Modifying the coupling plates.

distance of 11" from the center, as shown in Figure 13. These perforations match the external perforations of the intermediate coupling system, as shown in Figure 14. The intermediate coupling system consists of eight female threads of $\mathrm{W} 5 / 8^{\prime \prime}-18$ to fasten the drive shaft. Thus, the drive shaft will be attached directly to the plate and with the heads of the bolts internally for a free assembly and disassembly of this.

After the implementation of this solution, the desired improvements are achieved. Now the assembly system is simpler by not having to disassemble the male drive shaft from the dynamometer, and this makes the process more secure. Likewise, the process efficiency is increased by reducing by half the time needed for assembly. 


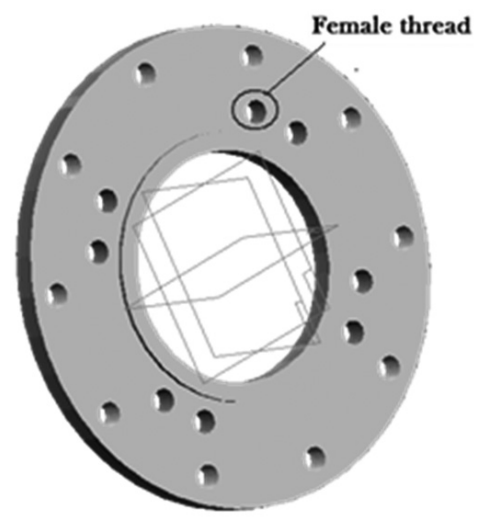

Figure I4. Intermediate coupling system.

\section{Key performance indicator analysis}

In this section, we present the key performance indicators (KPIs) ${ }^{29,30}$ that allow the evaluation of the success of the project (Table 7). Before the project, three to four motors were tested by month. After the improvement, four to six motors were tested in the same time, which on average means a savings of $12 \mathrm{~h}$ per month (Table 8).

Table 9 shows the benefits to the company resulting from the sustainable improvement process of the test engines. Quantitatively, the improvement allows one more torque-indication tests per month.

Table 10 shows the general results of the test process productivity. The main results were the annual increase in capacity of the torque-indication test and the

Table 7. Description of indicator type.

\begin{tabular}{ll}
\hline Indicator & Description \\
\hline Time & $\begin{array}{l}\text { Reduced testing time of the motors, thanks to the implemented improvement } \\
\text { Fiscal savings as a result of the improvements, some of which are manpower, installations and supplies. In } \\
\text { addition, it also considers the effect of additional sales resulting from newly available facilities } \\
\text { Indicators related with the quality of the product. In addition, it considers the reduction of the number } \\
\text { of failures and the improvement in efficiency and productivity } \\
\text { Quality-productivity }\end{array}$ \\
Safety & $\begin{array}{l}\text { Sedical leave, medical insurance or injuries as a result of dynamometer tests } \\
\text { Related to deficiencies or improvements encountered by the customer at the time of delivery and use of } \\
\text { the engine }\end{array}$ \\
\hline Client satisfaction &
\end{tabular}

Table 8. Times of assembly.

\begin{tabular}{llllll}
\hline Modification & Motor assembly $(\mathrm{h})$ & Part assembly $(\mathrm{h})$ & Dynamometer test $(\mathrm{h})$ & Dismantling $(\mathrm{h})$ & Total $(\mathrm{h})$ \\
\hline Before & $2-3$ & $3-4$ & $3-4$ & $2-3$ & $10-14$ \\
After & $0.5-0.7$ & $3-4$ & $3-4$ & $1-2$ & $7.5-10.7$ \\
\hline
\end{tabular}

Table 9. Costs-benefits.

\begin{tabular}{llllll}
\hline $\begin{array}{l}\text { Solution cost } \\
\text { (US\$) }\end{array}$ & $\begin{array}{l}\text { Test cost } \\
\text { (US } \$ \text { /h) }\end{array}$ & $\begin{array}{l}\text { Money saved the } \\
\text { solution (US\$/month) }\end{array}$ & $\begin{array}{l}\text { Approximate motor } \\
\text { maintenance cost (US } \$)\end{array}$ & $\begin{array}{l}\text { Additional sale for } \\
\text { monthly availability } \\
\text { (US } \$ / \text { month) }\end{array}$ & $\begin{array}{l}\text { Average annual } \\
\text { additional profits } \\
\text { (US\$/year) }\end{array}$ \\
\hline 485 & 90 & 1.080 & 50.000 & 60.000 & 720.000 \\
\hline
\end{tabular}

Table 10. Productivity/quality.

\begin{tabular}{|c|c|c|c|c|c|c|c|}
\hline Modification & $\begin{array}{l}\text { Approximate } \\
\text { sales } \\
\text { (US\$/year) }\end{array}$ & $\begin{array}{l}\text { Productivity } \\
\text { (additional } \\
\text { motors/year) }\end{array}$ & $\begin{array}{l}\text { Defective units }{ }^{a} \\
\text { (number/year) }\end{array}$ & $\begin{array}{l}\text { Downtime } \\
\text { (h) }\end{array}$ & $\begin{array}{l}\text { Lead time of } \\
\text { customer } \\
\text { (days) }\end{array}$ & $\begin{array}{l}\text { Increase of } \\
\text { productivity } \\
\text { (\%) }\end{array}$ & $\begin{array}{l}\text { Increase of } \\
\text { profits }^{d}(\%)\end{array}$ \\
\hline Before & $2,700,000$ & $48-54$ & 2 & 38 & 30 & 0 & 0 \\
\hline After & $3,420,000$ & $60-63$ & I & 24 & 30 & $|6-3|$ & 26 \\
\hline
\end{tabular}

ancomplete operational specifications from customer.

${ }^{b}$ Considering all maintenance stages for the engine.

${ }^{\mathrm{c}}$ Depend on type of engine to perform the maintenance.

${ }^{\mathrm{d}}$ Profits average with the new solution. 
Table II. Safety.

\begin{tabular}{llllr}
\hline Modification & $\begin{array}{l}\text { Injuries during } \\
\text { process of operation }{ }^{\mathrm{a}} \text { b } \\
\text { (number/year) }\end{array}$ & $\begin{array}{l}\text { Serious accidents } \\
\text { (number/year) }\end{array}$ & $\begin{array}{l}\text { Product cost of } \\
\text { medical leave }{ }^{c} \text { (US\$/year) }\end{array}$ & $\begin{array}{l}\text { Savings on } \\
\text { medical leave (\%) }\end{array}$ \\
\hline Before & 5 & 0 & 4,800 & 0 \\
After & 2 & 0 & 1,920 & 40 \\
\hline
\end{tabular}

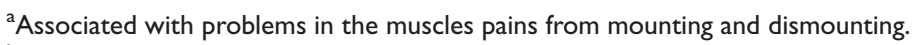

${ }^{b}$ Associated with the process of the dynamometer, but not mounting and dismounting.

${ }^{\mathrm{c} A v e r a g e ~ c o s t ~ o f ~ o p e r a t o r ~ h o u r s ~ c o r r e s p o n d s ~ t o ~} 40$ US $\$ / \mathrm{h}$.

Table I2. Customer satisfaction.

\begin{tabular}{llllll}
\hline Modification & $\begin{array}{l}\text { New clients landed } \\
\text { (number/year) }\end{array}$ & $\begin{array}{l}\text { Increased availability } \\
\text { to clients (\%) }\end{array}$ & $\begin{array}{l}\text { Percentage of } \\
\text { defects }^{\mathrm{a}}(\%)\end{array}$ & $\begin{array}{l}\text { Efficiency of the } \\
\text { process (\%) }\end{array}$ & $\begin{array}{l}\text { Costs for guarantees } \\
\text { (US\$/year) }\end{array}$ \\
\hline Before & 0 & 0 & 4 & 96 & 41,260 \\
After & 5 & 15 & 1.6 & 98.4 & 16,200 \\
\hline
\end{tabular}

${ }^{\mathrm{a}}$ Resulting from incomplete specifications from customers.

bHigher costs associated with transportation of parts and technical staff given the long distances.

reduction of defective units, both favoring an increase in productivity and benefits.

Table 11 specifies the decrease in medical leave (worker's compensation) that was a consequence of work accidents occurring during the development of manual maneuvers of the torque-indication test. Before the improvement, a high-risk manual process was required for the worker, a situation that has been eliminated, thanks to the improvement proposal. The economic value was calculated with the average (mean) costs of each work hour and the average (mean) number of medical leave (worker's compensation) related to the torque-indication tests. The decrease in number of defective motors directly influences the number of client complaints (see Table 12), which is associated with greater product satisfaction with the increase of the availability of regular maintenance, from both old and new customers.

\section{Discussion}

The presented integration attempts to help in the phases of problem-solving process starting from problem identification, solution concepts, implementation and finally the evaluation. However, it is important to add some considerations respect to the repeatability and level of the details for the analysis, such as the competences of the teamwork to develop the RCA and identification of contradictions, the time consumption to develop the analysis could be high if the teamwork do not have previous experience using TRIZ approach. Usability of TRIZ in different fields depends of the specific tool selected to analyze the problem and requirement.

Logic tree (PROACT) helps to describe, in a systematic, logical and visual way the failure modes, causes and effects. The benefit of using this diagram is understand clearly all the requirement to formulate the contradiction.

\section{Conclusion}

This work proposes a creative combination of RCA and TRIZ for identifying failure causes and proposing effective solutions. The advantages associated with the use of RCA to identify the causes of a problem are presented and the benefits that TRIZ provides in finding the definition of their possible solution are highlighted. ${ }^{31}$

The RCA-TRIZ approach constitutes an original systematic procedure for tackling problems related to events that occur at high frequency and/or high impact. In practice, successful application requires that wellformed teams are created in terms of qualified personnel and organizational commitment. The use of RCATRIZ allows finding critical faults and generating solutions, with a risk of insuccess lower than when using trial and error.

All possible hypotheses related to the material, design and manufacturing process are responsibility of the supplier. Therefore, by definition during the development of the RCA, the logical trees do not consider these scenarios as part of the future development and improvement options.

The proposal was successfully implemented and demonstrated on a real case of a torque test performed on truck engines used in high-tonnage mining operation. The last stage of this methodology was to track the implemented solution. For this, some KPIs were introduced, measuring the effectiveness of the implemented solutions.

One of the main difficulties of using TRIZ is the time to learn it properly and, consequently, the formation of 
work teams that meet the skills needed to develop the methodology. In terms of improving efficiency and effectiveness of solutions of a critical failure cause, it is advisable to work with multidisciplinary teams, because RCA and TRIZ methodologies cut across all areas of knowledge, requiring active participation of the people of the organization. Future work will aim at extending the integration of RCA-TRIZ, not just for generating solutions to specific problems but also for strategic analysis according to the evolution of technological systems and the impact of changes in the overall business strategy.

\section{Declaration of conflicting interests}

The authors declare that there is no conflict of interest.

\section{Funding}

This research received no specific grant from any funding agency in the public, commercial or not-for-profit sectors.

\section{References}

1. Prando R. Manual de Gestión de mantenimiento a la medida. Editorial Piedra Santa, San Salvador, El Salvador, 1996.

2. PAS 55-1:2008. Asset management. British Standard Institute, September 2008.

3. Barberá L, Crespo A, Viveros P, et al. Advanced model for maintenance management in a continuous improvement cycle: integration into the business strategy. Int $J$ Syst Assur Eng Manag 2012; 3(1): 47-63.

4. Moubray J. Reliability-centered maintenance. 2nd ed. New York: Industrial Press, Inc., 1997, p.448.

5. Rasmuson DM and Kelly DL. Common-cause failure analysis in event assessment. Proc IMechE, Part $O: J$ Risk and Reliability 2008; 222(4): 521-532.

6. US Department of Energy (DOE). Root cause analysis guidance document. DOE guideline, US Department of Energy, Washington, DC, Febrero 1992.

7. Latino RJ and Latino KC. Root cause analysis: improving performance for bottom-line results. 2nd ed. Boca Raton, FL: CRC Press LLC, 2002.

8. Mobley RK. Root cause failure analysis. Woburn, MA: Butterworth-Heinemann, 1999.

9. Hurdle EE, Bartlett LM and Andrews JD. System fault diagnostics using fault tree analysis. Proc IMechE, Part O: J Risk and Reliability 2007; 221(1): 43-55.

10. Xing L, Boddu P, Sun Y, et al. Reliability analysis of static and dynamic fault-tolerant systems subject to probabilistic common-cause failures. Proc IMechE, Part $O: J$ Risk and Reliability 2010; 224(1): 43-53.

11. Cornell K. WebKaizen, better faster cheaper problem solving for business. Omaha, NE: Prevail Digital Publishing, 2010.

12. Osborn AF. Applied imagination: principles and procedures of creative problem solving. 3rd ed. New York: Charles Scribner's Sons, 1963.
13. Sutton RI and Hargadon A. Brainstorming groups in context: effectiveness in a product design firm. Admin $\mathrm{Sci}$ Quart 1996; 41(4): 685-718.

14. Michalko M. Thinkertoys: a handbook on creative-thinking techniques. 2nd ed. Berkeley, CA: Ten Speed Press, 2006.

15. Tanner D. Total creativity in business \& industry. Editorial Advanced Practical Thinking Inc, 1997. ISBN-10: 0780767993 ;ISBN-13: 978-0780767997.

16. Altshuller GS. Creativity as an exact science: the theory of the solution of inventive problems (original publication in Russian-1979). New York: Gordon \& Breach Science Publishers, 1984.

17. Ahmed R, Koo JM, Jeong YH, et al. Design of safetycritical systems using the complementarities of success and failure domains with a case study. Reliab Eng Syst Safe 2011; 96: 201-209.

18. Flaus J-M. A model-based approach for systematic risk analysis. Proc IMechE, Part O: J Risk and Reliability 2008; 222(1): 79-93.

19. Modarres M and Cheon SW. Function-centered modeling of engineering systems using the goal tree-success tree technique and functional primitives. Reliab Eng Syst Safe 1999; 64: 181-200.

20. Ulwick A. What customers want: using outcome-driven innovation to create breakthrough products and services. New York: McGraw-Hill, 2005.

21. ISO/DIS 14224:2004. Petroleum, petrochemical and natural gas industries - collection and exchange of reliability and maintenance data for equipment.

22. Sinnamon RM and Andrews JD. New approaches to evaluating fault trees. Reliab Eng Syst Safe 1997; 58: 89-96.

23. Fey V and Rivin E. Innovation on demand: new product development using TRIZ. New York: Cambridge University Press, 2005.

24. Savransky S. Engineering of creativity: introduction to TRIZ methodology of inventive problem solving. 1 st ed. Boca Raton, FL: CRC Press, 2000.

25. Cavallucci D, Rousselot F and Zanni C. Linking contradictions and laws of engineering system evolution within the TRIZ framework. Creativ Innovat Manag 2009; 18(2): $71-80$.

26. Cascini G, Rotini F and Russo D. Synthesis in innovation. Capitulo: networks of trends: systematic definition of evolutionary scenarios. Procedia Eng 2011; 9: 355-367 (Proceeding of the ETRIA world TRIZ future conference 2008, Italy 2008).

27. Becattini N, Cascini $G$ and Rotini F. Correlations between the evolution of contradictions and the law of ideality increase. In: Proceedings of the 9th ETRIA TRIZ future conference (sponsored by CIRP), Timisoara, Romania, 4-6 November 2009, pp.26-34 (Republished on Procedia Eng 2011; 9: 236-250).

28. Cavallucci D. Integrating Altshuller's development laws for technical systems into the design process. CIRP Ann: Manuf Techn 2001; 50(1): 115-120.

29. Loh TC and Koh SCL. Critical elements for a successful enterprise resource planning implementation in small-and medium-sized enterprises. Int J Prod Res 2004; 42(17): 3433-3455.

30. Cheung SO, Suen HCH and Cheung KKW. PPMS: a web-based construction project performance monitoring system. Automat Constr 2004; 13(3): 361-376.

31. Viveros $\mathrm{P}, \mathrm{Zio} \mathrm{E}$, Nikulin $\mathrm{C}$, et al. Integration of root cause analysis and theory of inventive problem solving. 
In: Proceedings of the 11th international probabilistic safety assessment and management conference and the annual European safety and reliability conference, Helsinki, Finland, 25-29 June 2012.

32. Liang K. Optimizing Unilever's capital and emergency spare stock sizes. A thesis for the Degree of Bachelor of Applied Science, Mechanical \& Industrial Engineering, University of Toronto, Canada, 2009.

33. Pascual R, Del Castillo G, Louit D, et al. Businessoriented prioritization: a novel graphical technique. Reliab Eng Syst Safe 2009; 94: 1308-1313.

34. Wang Y-F, Xie M, Habibullah MS, et al. Quantitative risk assessment through hybrid causal logic approach. Proc IMechE, Part O: J Risk and Reliability 2011; 225(3): 323-332.

35. Stone \& Webster Engineering Corporation, Greenberg HR and Cramer JJ. Risk assessment and risk management for the chemical process industry. New York: John Wiley \& Sons, Inc., 1991.

36. Smith DJ. Reliability, maintainability and risk: practical methods for engineers. 5th ed. Waltham, MA: Butterworth-Heinemann, 1997.

37. Vaidhyanathan R and Venkatasubramanian V. Digraphbased models for automated HAZOP analysis. Reliab Eng Syst Safe 1995; 50: 33-49.

38. Marsh DWR and Bearfield G. Generalizing event trees using Bayesian networks. Proc IMechE, Part O: J Risk and Reliability 2008; 222(2): 105-114.

39. Wilson A, Limnios N, Keller-McNulty S, et al. Modern statistical and mathematical methods in reliability (series on quality reliability and engineering statistics), vol. 10. Singapore: World Scientific Publishing Co. Pte. Ltd, 2005.

40. Eversheim W. Innovation management for technical products: systematic and integrated product development and production planning. Berlin and Heidelberg: SpringerVerlag, 2009.

\section{Appendix I}

\section{Complementary tools for root cause analysis}

Some of the tools require greater expertise than others and an adequate team, which could typically consist of the following (Table 13):
- Operator: an expert in management and operation of the systems and equipment under analysis.

- Maintainer: expert in repair and maintenance of the systems and equipment under analysis.

- Programmer: offers a systemic view of the activity.

- Specialist: expert in specific domain areas.

- Facilitator: methodological advisor.

- Process engineer: provides overview of the production business.

The roles that these members have in the application of root cause analysis (RCA) are shown in Figure 15.

\section{Appendix 2}

\section{Features of TRIZ methodology}

1. Physical contradiction resolution and separation principles. To analyze physical contradictions, the following steps are performed:

Step 1. Capture the functions involved in the conflict and establish a functional model for the contradiction.

Step 2. Identify the physical contradiction.

Step 3. Identify the areas of conflict, in space and time.

Then, various approaches can be undertaken to separate the physical contradictions:

- Approach 1: separation in space. The contradictory requirements or functions of a system can be separated into different spatial regions, for example, according to the subsystems distribution, so that these subsystems can perform their own functions without negatively affect the others (e.g. hospitals are often separated into different departments and space zones (ophthalmologist, pediatric, etc.) or supermarkets create different places for food and chemical products).

Table 13. Complementary tools for RCA.

\begin{tabular}{|c|c|}
\hline Tool & Description \\
\hline Pareto analysis ${ }^{33}$ & $\begin{array}{l}\text { It is used to prioritize critical equipment in a system; this approach is very useful for decision } \\
\text { making on a small set of systems and failure modes } \\
\text { It is based on the principle that } 20 \% \text { of the causes create } 80 \% \text { of the problems }\end{array}$ \\
\hline Jackknife ${ }^{33,34}$ & $\begin{array}{l}\text { It is used to prioritize critical equipment in a system. Allows to discriminate between equipment } \\
\text { or parts that cause the most downtime, while at the same time allows evaluating whether this is } \\
\text { due to high frequency of occurrence or long downtime }\end{array}$ \\
\hline Costs scatter diagram ${ }^{34}$ & It is used to prioritize critical equipment in terms of costs \\
\hline What if? analysis 35,36 & It is used to identify hazards or risks in the processes \\
\hline HAZOP $26,37,38$ & $\begin{array}{l}\text { It is used to identify hazards or risks in the processes. It is based on the premise that accidents } \\
\text { occur as a result of a deviation of process parameters with respect to the normal operating values }\end{array}$ \\
\hline Bayesian networks ${ }^{39,40}$ & $\begin{array}{l}\text { It is used for diagnosis (to determine the possible causes of a failure) as well as to generate a } \\
\text { prediction (to predict the effects of a failure) }\end{array}$ \\
\hline
\end{tabular}




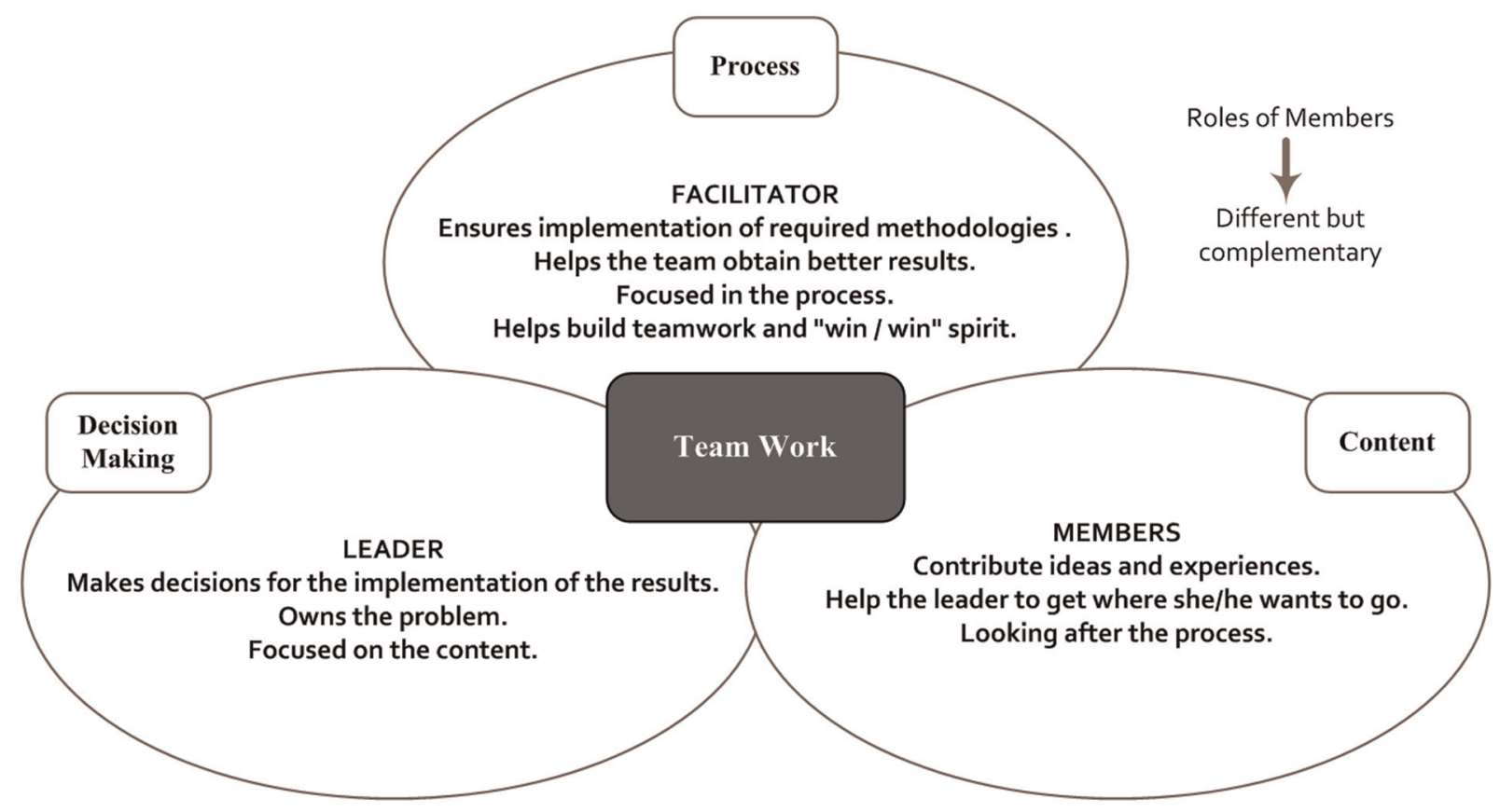

Figure 15. Roles of RCA team members. ${ }^{8}$.

- Approach 2: separation in time. The contradictory requirements of a system can be separated into different time intervals, so that these requirements or functions can be met or operate at different time schedules without negatively affecting the others (e.g. in case of variable manufacturing cycles, a company can temporarily hire more people; cinemas offer discounts in different periods to balance customer demands).

- Approach 3: separation between the whole and its parts. The contradictory requirements can be overcome by distinguishing the property of the whole system with respect to its subsystems (e.g. a company with a large and diversified network of very specialized suppliers is flexible as a general-purpose manufacturer, but professional as an expert in the field.).

- Approach 4: separation upon conditions. The contradictory requirements can be separated by changing the condition settings (e.g. a Mexican restaurant cooking the same dish with different levels of "hotness" upon condition of customer taste.)

2. Inventive principles. Altshuller defined 39 technical parameters, which allow most of the technical contradictions in engineering system to be described. ${ }^{24,40}$ With these parameters, a matrix of $39 \times 39$ contradictions can be generated to resolve the technical contradictions that appear.

Also, Altshuller identified 40 inventive principles that were used to solve the problems in the patents analyzed by him, distributed in the matrix of contradictions, which in the rows of the matrix put the parameters to improve and in the columns the parameters that worsen with the modification of the parameters improved. ${ }^{24,40}$

3. Implementation of the TRIZ methodology. The steps for the implementation of the TRIZ methodology are as follows:

- Step 1: particular or specific problem. After finding the problem with RCA, it is required to transform the particular problem in an analogical language based on the 39 technical parameters defined by TRIZ. Any problem can be presented as an analogue problem, which will have a particular contradiction.

- Step 2: analogue problem. In this stage, the matrix of contradictions must be used. The matrix function is to show how other general problems (analogue to the specific problem) have been resolved in other instances.

- Step 3: analogue solution. These solutions are called inventive principles.

- Step 4: specific solution. When using analogue solutions, the specific problem is sought to be solved.

Functional improvement methods to improve the delivery of the useful function and eliminate or contain the harmful function. Some examples are as follows:

- Method 1. Cover the missing element in a model subject-action-object.

- Method 2. Add a subject and field to create an adequate useful action.

- Method 3. Improve the object.

- Method 4. Improve the field. 
Some examples of methods to eliminate and contain a harmful function are as follows:

- Method 1. Block or disable the harmful action (field).

- Method 2. Add another field or fields to compensate the harmful action (field).

- Method 3. Pass the harmful action (field) to another object.

- Method 4. Fix or replace the subject of a harmful action.
- Method 5. Fix or replace the object of a harmful function.

Furthermore, the elimination or reduction in the number of parts can eliminate redundant functions (those that provide little or no benefit to customers), thereby simplifying and streamlining the system. This reduces the complexity and costs. 